\title{
Factors Influencing Iron Treatment among Anemic Pregnant Women
}

\author{
Ashgan A. Abd El Latef ${ }^{*}$, Gehan E. Ghonemy ${ }^{2}$, Rania M. Abd El Ghany ${ }^{3}$, Magdy Ibrahim ${ }^{4}$ \\ ${ }^{1}$ B.Sc. of Nursing, Midwifery Master Student, Cairo University, Al Orman, Giza Governorate 12613, Egypt \\ ${ }^{2}$ Assistant- Professor, Maternal \& Newborn Health Nursing, Faculty of Nursing, Cairo University, Al Orman, Giza Governorate 12613, Egypt \\ ${ }^{3}$ Lecturer, Maternal \& Newborn Health Nursing, Faculty of Nursing, Cairo University, Al Orman, Giza Governorate 12613, Egypt \\ ${ }^{4}$ Professor of Obstetrics \& Gynecology, Faculty of Medicine, Cairo University, Al Orman, Giza Governorate 12613, Egypt
}

\author{
DOI: $10.36348 /$ SJNHC.2019.v02i10.003 \\ | Received: 20.09.2019 | Accepted: 27.09.2019| Published: 22.10.2019 \\ *Corresponding author: Ashgan A. Abd El Latef
}

\section{Abstract}

Background: Iron deficiency anemia (IDA) has a negative impact on women reproductive health, causing impaired cognitive abilities and decreased physical performance. Aim: to assess the factors influencing iron treatment among anemic pregnant women. Research Design: Correlational descriptive research design was adopted for this study. Setting: The primary health care unit in El-Baranea is affiliated to directorate of health in Ashmon El-Menofea. Sample: A Purposive sample of 150 pregnant women was recruited for the study. Tool: Two tools were used for data collection I) structured interviewing questionnaire, II) Self-report practices questionnaire. Results: most of the sampled women had malpractices in their nutritional habits \& in receiving the iron treatment although they complied to take iron treatment every day. There was a relationship between the level of knowledge about iron treatment and the level of education $(p \leq 0.05)$. Conclusion: There are many factors influencing iron treatment as women's level of knowledge and malpractices in receiving their iron treatment. Recommendation: Continuous health education for all women who receive iron treatment should be provided in antenatal clinic.

Keywords: Factors, pregnancy, iron deficiency anemia.

Copyright @ 2019: This is an open-access article distributed under the terms of the Creative Commons Attribution license which permits unrestricted use, distribution, and reproduction in any medium for non-commercial use (NonCommercial, or CC-BY-NC) provided the original author and source are credited.

\section{INTRODUCTION}

Anemia from Greek Anemia, "meaning without blood" is as a condition in which either the number of red blood cells (RBCs) decreased or their oxygen-carrying capacity reduce to meet the body normal physiologic functions. Anemia is especially common in women of reproductive age and particularly during pregnancy [1].

Iron deficiency anemia is an important public health problem for pregnant women, living in developing countries affecting two thirds of pregnant women and contributing to maternal morbidity and mortality, poor socio economical and educational statuses are the principal reasons for high prevalence of anemia in development areas. It is estimated that $20-$ $50 \%$ of the world population is suffering from iron deficiency anemia. Iron deficiency is believed to be the most common cause of anemia in pregnancy [2].

The British Committee for Standards in Hematology (BCSH, 2011) defines Iron Deficiency Anemia (IDA) in Pregnancy as hemoglobin ( $\mathrm{Hb})$ less than $11 \mathrm{mg} / \mathrm{dl}$ in the first trimester and less than
$10.5 \mathrm{mg} / \mathrm{dl}$ in the second and third trimesters and less than $10 \mathrm{mg} / \mathrm{dl}$ in the postnatal period. The BCSH set standard for hematological assessment for every pregnant woman [3].

Anemia is associated with increased pre-term labor $(28.2 \%)$, pre-eclampsia $(31.2 \%)$ and maternal sepsis and Iron deficiency anemia (IDA) increases the risk of ante partum hemorrhage (APH), postpartum hemorrhage (PPH) and delayed healing of perinatal trauma or caesarean section wounds. It also affects breast feeding, milk quality and quantity with lactation being interrupted or stopped as a result of the poor supply and excessive fatigue. The effects of IDA on the fetus and the newborn are as significant as those for the mother; poor nutrient levels lead to poor uterine growth, decreased liquor, asymmetrical growth patterns, small for gestational age, premature delivery and low birth weight [3].

Iron deficiency anemia (IDA), is a type of microcytic and hypochromic anemia, occurs when an individual's iron supply is lower than the physiological amount required for the production of hemoglobin $(\mathrm{Hb})$. Among other processes, $\mathrm{Hb}$ is a key component of 
tissue oxygenation, cellular function, and cell development. Hemoglobin $(\mathrm{Hb})$ level indicates the amount of circulating $\mathrm{Hb}$ proteins, which are attached to red blood cells (RBCs) and make up the body's usable form of iron. As one of the most severe and widespread nutritional deficiencies, IDA typically occurs when an individual's iron intake is insufficient or when there is a complication with absorption. Iron deficiency anemia (IDA) is classified as a hematologic disorder and is multifactorial in nature. Common causes of IDA vary in their potential for modification as they range from population demographics to lack of iron-rich foods [4].

Three levels of anemia during pregnancy are severe anemia when hemoglobin concentration is less than $7.0 \mathrm{~g} / \mathrm{dL}$, moderate when hemoglobin falls between 7.0-9.9 $\mathrm{g} / \mathrm{dL}$ and mild anemia when hemoglobin level range from 10.0 to $11.0 \mathrm{~g} / \mathrm{dL}$. IDA can be manifested by general signs and symptoms that range in severity and depend on the significance of an individual's condition. Since some symptoms are nonspecific, general, and easily confused as resulting from another health condition or everyday cause, IDA can go unnoticed and undiagnosed for an extended period of time. Pallor, loss of energy, or weakness, and exertion dyspnea are cardinal signs and symptoms of IDA across all populations. These signs and symptoms are a result of the abnormally low amount of oxygen circulating to body tissues. This low oxygen level is represented by a reduced $\mathrm{Hb}$ level as well as other diagnostic lab values [5].

In every case of anemia the diagnostic set-up should be focused on revealing the cause(s) of anemia, which may be a single cause or perhaps several causes working in synergy, for example concomitant folate, vitamin B12 or vitamin B-complex deficiency [6].

\section{Significance of the Study}

Iron deficiency anemia is the most common form of anemia. Since 1992 until now the minister of health implementing program for preventive treatments of Iron Deficiency Anemia in Pregnancy, produce the efforts to decrease iron deficiency during pregnancy in order to sake the mortality and morbidity rate according to WHO [7]. Nevertheless, there is little information about determinant of the factors influencing iron treatment among anemic pregnant women. And also with this program iron deficiency anemia still present.

Although there is an implementing program by the Ministry of Health regarding iron treatment for all the pregnant women on the primary health care unit in El-Baranea- Ashmon, iron deficiency anemia is still considered health problem, as it affects about $41 \%$ of pregnant women who attended this primary health care unit (PHCU) according to base line data at 2014 and the prevalence rate of anemia among pregnant Women increased to reach $58 \%$ in 2015 . So, the current research will explore the factors that influencing iron treatment among anemic pregnant women.

Moreover, these finding will be documented and reported to the authorative personnel who responsible about the implementation of the program in the primary health care unit to develop a new guidelines to be implemented by the health care personnel in the PHCU to follow and closely monitor these mothers to improve maternal and fetal wellbeing.

The findings of this study will be considered as a base line data that improve the knowledge and awareness of the health care providers include nurses about the factors that influencing iron treatment among anemic pregnant women. Also, these finding will help the nurses to monitor, assess, educate and detect any abnormal findings related to low hemoglobin level.

\section{METHODS}

Aim of Study

This study aimed to assess the factors influencing iron treatment among anemic pregnant women

\section{Research Questions}

- What are the Factors influencing iron treatment among anemic pregnant women in El-Baranea primary health care unit?

- What is the relation between the factors influencing iron treatment and level of anemic among anemic pregnant women?

\section{Research Design}

Correlational descriptive design as it examines the relation between the factors those influence iron treatment among anemic pregnant women and was utilized to achieve the study aim.

\section{Setting}

The primary health care unit in El-Baranea is affiliated to directorate of health in Ashmon ElMenofea. This unit provides services for families from birth to death, for all mothers and babies \& follow up for all pregnant women from the first to third trimester, provide vaccines for the pregnant women, follow up after delivery (post-partum) and family planning counseling.

\section{Sample}

Purposive sample of pregnant women were recruited. Pregnant women were recruited for the study during a period of 6 months.

\section{Tool of Data Collection}

It was designed by the research investigator after reviewing of the related literature review. To collect the necessary data that covers the aim of the study. 


\section{First Tool}

A structured interviewing questionnaire (Appendix I) which consisted of;

Part-1: Demographic data including: age i.e. categorized as (from 20 to 25 years \& from 25 to less than 35years \& more than 35 years), education level i.e. (read and write \& not read and not write \&primary \& preparatory \&secondary school\& college graduate), occupation (work or not work) and family income i.e. categorized as $(250-<400 \&$ $400-<550 \&$ more than), residence i.e. (urban-rural), numbers of rooms in the home.

Part-2: Obstetric history: past obstetric history and data related to current pregnancy i.e. (Gestational age in weeks, Parity, Birth spacing in years, the first day of the last menstrual period and the expected date of delivery).

Part-3: Medical history includes chronic diseases such as diabetes and hypertension. And laboratory finding for hemoglobin level.

Part-4: Factors influencing iron treatment among anemic pregnant women included subparts:

- Nutritional habits: For example do you know the types of foods rich with iron? And body mass index (BMI).

- Vitamin supplementation. Do you known the types and names of the vitamins that you take?

- Absorption of iron. Habits with iron treatment (i.e. Are you drinking tea after meal directly?).

\section{Second Tool}

Self-report practices questionnaire (Appendix I): it includes the practice reported by the mothers and her relative.

Scoring of the questionnaire as following: score 1 indicates correct knowledge and practice related to iron treatment, score 0 indicates wrong knowledge and practice related to iron treatment. The total knowledge score more than $50 \%$ indicate satisfactory level of knowledge while the scores less than 50\% indicate unsatisfactory level of knowledge.

\section{Procedure}

The research investigator obtained the acceptance from the governorate of health in Ashmaon El Menofea and then introduced her to the pregnant mothers and explained the purpose of the study in order to obtain their written consent to participate in the study to gain their cooperation.

Blood sample was analyzed in the lab of the primary health care unit of El-Baranea to test hemoglobin concentration and complete blood count was documented to indicate IDA (microcytic hypochromic anemia).
All pregnant women who matched the inclusion criteria were recruited for the study, each pregnant women was interviewed individually to collect demographic data, obstetrical, medical history and assess the factors influence iron treatment among anemic pregnant women as awareness, knowledge related practice of iron treatment, lifestyle habits for each mother including (nutrition, compliance of oral iron, vitamins with iron, absorption of iron). The interviewing time was 15 minutes.

\section{RESULTS}

This chapter describes the results of the current study which aimed to assess factors influencing iron treatment among anemic pregnant women at El-Baranea primary health care unit. Results of the study divided into five parts; the first part: description of the sample characteristics by their socio- demographic data, obstetrical history, the medical history, laboratory finding and BMI. The second part: include the factors influence on iron treatment effect. The third part: selfreported practices of the women related to iron treatment. And the fourth part includes the relationship between women's knowledge and practices in receiving iron treatment and their levels of anemic. And fifth part includes relationship between relationship between women's levels of knowledge about iron treatment and their socio-demographic characteristic

\section{The First Part. Description of the Sample Characteristics Socio-Demographic Characteristics}

Table-1: Distribution of the sample according to their socio-demographic characteristics

\begin{tabular}{|l|l|l|}
\hline Items & $(\mathbf{n}=150)$ & $\%$ \\
\hline Age class/years & 68 & 45.3 \\
\hline $20-25 y$. & 76 & 50.7 \\
\hline 25-35 y. & 6 & 4.0 \\
\hline More than 35y. & 5 & 3.3 \\
\hline Mather's level of education \\
\hline Not Read or write & 7 & 4.7 \\
\hline Read and write & 13 & 8.7 \\
\hline Primary school & 35 & 23.3 \\
\hline Preparatory education & 8 & 5.3 \\
\hline Secondary school & 9 & 6.0 \\
\hline University level & 19 & 12.7 \\
\hline Working state & 131 & 87.3 \\
\hline Employee \\
\hline House wife & 8 & 5.3 \\
\hline Level of income & 48 & 32.0 \\
\hline 250-400EP & 94 & 62.7 \\
\hline 400 EP to less than550 EP & 48 \\
\hline More than 550EP & \multicolumn{3}{|l}{} \\
\hline No. of Family members & 45 & 30.0 \\
\hline Two persons & 51 & 34.0 \\
\hline Tree persons \\
\hline More than three & 54 & 36.0 \\
\hline \multicolumn{3}{|l|}{}
\end{tabular}


Results of the present study indicated that the woman's age ranged from 20 to more than 35 years old with average mean age of $25.7 \pm 4$. $86 \mathrm{SD}$ years old. $23.3 \%$ of women had preparatory education, $87.3 \%$ were house wives. Regarding to family income was described into levels ranged from 250 to more than 550Egyption pounds (EPs) per month, $62.7 \%$ of the sample was more than 550EPs. As regard the family numbers $30.0 \%$ of the sample was newly married,
$34.0 \%$ had only one child, $36.0 \%$ had more than one child (Table-1).

\section{Obstetrical History}

This part contains two main subparts past obstetric history and current gestational age. a) Past obstetrical history which includes number of previous pregnancies, mode of previous delivery, duration between children, number of living child, and number of previous abortion. b) Current gestational age.

Table-2: Distribution of the pregnant women according to previous obstetric history

\begin{tabular}{|l|l|l|}
\hline \multicolumn{1}{|l|}{$(\mathrm{n}=150)$} & \\
\hline Items & freq. & $\%$ \\
\hline Number of previous delivery & & \\
\hline Primigravida & 45 & 30.00 \\
\hline Gravida 2 & 51 & 34.00 \\
\hline Gravida 3 & 29 & 19.33 \\
\hline Grand gravid & 25 & 16.70 \\
\hline Mode of previous delivery & $\mathbf{N = 1 0 5})$ & \\
\hline Normal vaginal delivery & 39 & 26.00 \\
\hline Cesarean section & 66 & 44.00 \\
\hline Interval between children & & $\mathbf{N = 1 0 5}$ \\
\hline One year & 43 & 28.70 \\
\hline Two year & 58 & 39.70 \\
\hline More than three year & 4 & 2.70 \\
\hline Living child & $\mathbf{( N = 1 0 5 )}$ & \\
\hline One child & 53 & 35.33 \\
\hline Two child & 35 & 23.33 \\
\hline Three child & 15 & 10.00 \\
\hline Four child & 2 & 1.33 \\
\hline
\end{tabular}

\section{Past Obstetrical History}

Regarding the obstetric history data revealed that most of the pregnant women in the sample were second gravida $(34.0 \%)$, their previous delivery was C.S $(44.0 \%)$ had one child $(35.3 \%)$ and the duration between the each child was almost two years $(39.7 \%)$ Regarding the previous abortion only $28.0 \%$ of the study sample had only one abortion (Table-2).

\section{DISCUSSION}

Anemia in pregnant women constitutes a real concern in developing country all over the world. The current study aimed to assess the factors those influence iron treatment among anemic pregnant women. Discussion of the findings in the present study is focusing on the following domains: 1) factors influence on iron treatment effect, 2) the relationship between women's knowledge and practices in receiving iron treatment and their levels of anemia, and 3) relationship between the socio-demographic characteristics of the sample and their level of knowledge.

\section{Factors Influence on Iron Treatment Effect}

Results in the present study denoted that, most of the sample had mal practices in their nutritional habits and in receiving the iron treatment, although they complied to take the iron treatment every day, and they did not have correct information about it. Elashiry ElGhazali \& Habil [8] reported that the dietary risk factors, deficient weekly intake of meat, chicken, fish, vegetables, fruits and excess daily consumption of tea were associated with anemia. Further, women who received an educational guideline about iron deficiency anemia and its treatment gained knowledge better than women who didn't receive it [2].

The results are in the same line with Abd ElHameed, Mohammed \& Abd El-Hameed [2] who conducted study about the effect of nutritional educational guidelines on women with iron deficiency anemia and reported that about $67.5 \%$ of total sample of 200 pregnant women have irregular meals before receiving the educational session. Also, Lertmulligaporn [9] who found that the compliance rate in receiving iron treatment was about $75 \%$ and Mailman [6] reported that about half of his sample complied with daily vitamins and minerals. The prevalence of compliance in the study of Sushila, Ritu, Smiti and Sonika [10] was $80.47 \%$. Further, the results of the study of Mosleh [11] have shown that, there was gradual decrease of knowledge and awareness concerning the effect of tea with meals on iron absorption, where the data have shown that many 
women were not aware and had lack of knowledge that tea with meals decrease iron absorption in the blood.

On the other hand, Haile et al., [12] in their results reported that only $18.0 \%$ of total sample of 405 complied with the iron folic acid supplementation. And the results of Sushila, Ritu, Smiti and Sonika [10] who reported that, the pregnant women had enough information about iron treatment, understood and strictly followed the instructions given by the doctor. Moreover, Raksha et al., [13] study Knowledge, attitude and practice regarding anemia among pregnant women and reported that $(46 \%)$ of the pregnant women already know the food rich with iron.

\section{SUMMARY, CONCLUSION AND RECOMMENDATION SUMMARY}

The current study aimed to assess the Factors influencing iron treatment among anemic pregnant women. This chapter summarizes findings of the current study, and suggested recommendations with implications for nursing practices, research and education.

The main finding of the current study revealed that:

- Results of the present study reported that the woman's age ranged from 20 to more than 35 years old with average mean age of $25.7 \pm 4$. 86 SD years old. $23.3 \%$ of women had preparatory education, $87.3 \%$ were house wife. Regarding to family income was described into levels ranged from 250 to more than 550Egyption pounds (EPs) per month, $62.7 \%$ of the sample be more than 550EPs. As regard the family numbers $30.0 \%$ of the sample was newly married, $34.0 \%$ had only one child, $36.0 \%$ had more than one child.

- Regarding the obstetric history data revealed that most of the pregnant women in the sample was second gravida $(34.0 \%)$, their previous delivery was C.S (44.0\%) had one child $(35.3 \%)$ and the duration between the each child they had almost two years $(39.7 \%)$ Regarding to previous abortion only $28.0 \%$ of the study sample had only one abortion.

- Result of the study reported that their gestational age ranged from $20-38$ weeks gestational with mean of $26.39 \pm 3.87 \mathrm{SD}$.

- Present study's results denoted that about $30 \%$ of women had previous history of anemia in their previous pregnancy. On assessing women hemoglobin levels in the current pregnancy, , most of sample had moderate anemia, the $\mathrm{Hb}$ level with mean of $9.50 \pm 7.02 \mathrm{SD}$ g/dl, the complete blood count (CBC) conclusion as diagnosed was microcytic hypochromic anemia (MHA).

- The average drinking of tea per day was two times $48.0 \%$. Further, $91.3 \%$ of the sample drinking tea after taking oral iron, $86.7 \%$ drinking milk after having oral iron. On the other hand, $82 \%$ eating food rich with iron, $90 \%$ eating vegetables rich with iron and $49.7 \%$ eating fresh leafy green vegetables.

- Result reported that $92.7 \%$ of the sample didn't know the importance of iron as a treatment of anemia, While $94 \%$ didn't know the side effect of oral iron, Also 94\% didn't know the precaution must be taken during take oral iron. Further, $92.7 \%$ didn't know the effect of iron deficiency anemia on woman and $94.7 \%$ didn't know A the effect of iron deficiency anemia on their fetuses.

\section{CONCLUSION}

Based on the finding of the current study it's concluded that, although the pregnant women received iron treatment during their pregnancy according to the protocol of the $\mathrm{MCH}$ center at el Barania, the hemoglobin level still low as a results of many factors (i.e. knowledge, practices and nutritional factors). Further, there were no relationship between women's levels' of anemia and gravidity, age and income. While there was a significant relationship between women's levels of anemia and the educational level.

\section{RECOMMENDATIONS}

Based on the finding of the current study, the following recommendations suggested:

- Health education must be given by health care team (physician, nurses) to all pregnant women pre\& during their pregnancy to increase their awareness.

- Follow up should be carried out for early detection of iron deficiency anemia among pregnant women at rural areas.

- An educational booklet includes information about IDA (i.e. balanced diet, types of food rich with iron, and how to avoid poor practices).in $\mathrm{MCH}$ centers or in primary health care units should be provided to all pregnant women.

\section{REFERENCES}

1. Shams, S., Ahmad, Z., \& Wadood, A. (2017). Prevalence of Iron Deficiency Anemia in Pregnant Women of District Mardan. Pakistan. Journal of Preg Child Health, 4(356), 2.

2. ElHameed, H. S. A., Mohammed, A. I., \& El Hameed, T. A. (2012). Effect of nutritional educational guideline among pregnant women with iron deficiency anemia at rural areas in kalyobia governorate. Life Sci J, 9(2), 1212-17.

3. Pease, S. (2016). Iron Deficiency Anemia in Pregnancy and Childbirth, M19 v4, P3.

4. Cox, A. J. (2016). The Effects of Iron Deficiency Anemia and Iron Supplementation in Pregnancy.

5. American Society of Hematology. (2016). Blood Disorders: Anemia. American Society of Hematology: Helping Hematologists Conquer Blood Diseases Worldwide. Retrieved from http://www.hematology.org/Patients/Anemia. 
6. Mailman, N. (2015). Iron Deficiency and Anemia in Pregnant Women in Malaysia Still A Significant and Challenging Health Problem. Journal Pregnancy Child Health, 2(3).

7. WHO, U. (2012). UNFPA, The World Bank. Trends in maternal mortality: 1990 to 2010. World Health Organization, UNICEF, UNFPA, and The World Bank.

8. Shaaban OM, Abbas AM, Hafiz HA, Abdelrahman AS, Rashwan M, Othman ER. Effect of pregnancy-lactation overlap on the current pregnancy outcome in women with substandard nutrition: a prospective cohort study. Facts, views \& vision in ObGyn. 2015 Dec 28;7(4):213.

9. Lertmulligaporn, N. (2000). Thailand [M.S. Thesis in Nutrition Bangkok: Faculty of Graduate Studies, Mahidol University.

10. Godara, S., Hooda, R., Nanda, S., \& Mann, S. (2013). To study compliance of antenatal women in relation to iron supplementation in routine antenatal clinic at a tertiary health care centre. Journal of Drug Delivery and Therapeutics, 3(3), 71-75.

11. Mosleh M, Williams RJ, Franx M, Kriek M. The Evolution of the Mass-Size Relation to $\mathrm{z}=3.5$ for UV-bright Galaxies and Submillimeter Galaxies in the GOODS-North Field. The Astrophysical Journal. 2010 Dec 22;727(1):5.

12. Tegegne, M. (2017). Compliance to prenatal Iron and Folic acid supplement and associated factors among women during pregnancy in South East Ethiopia: A Cross-sectional study. Global Journal of Medical Research, 7(2).

13. Raksha, M., \& Shameem, V. (2016). Knowledge, attitude and practice study regarding anemia in antenatal women. International Journal Reprod Contracept Obstetrics Gynecology, 5(7), 2101-3. 